\title{
Confidence-Sourcing Among Amateur Soccer Players: Interpreting Time, Place and Stimulus-Relevance
}

\author{
Paul K. Miller ${ }^{1, *}$, Robert George ${ }^{2}$ and Steven Nicholson ${ }^{3}$ \\ ${ }^{I}$ Department of Medical and Sport Sciences, University of Cumbria, UK; ${ }^{2}$ British Cycling, UK \\ ${ }^{3}$ Department of Psychology, Lancaster University, UK
}

\begin{abstract}
Although confidence is one of the major contemporary concerns in the psychology of sporting performance, extant study has primarily been concerned with elite and/or individual sports, and a deductive framework has been dominant. Drawing upon the core techniques of Straussian Grounded Theory, the research reported in this paper inductively analyses detailed accounts of confidence-sourcing provided by $\mathrm{N}=14$ seasoned participants in amateur soccer. Results reveal a number of (sometimes eclectic) features of the ways that these individuals interpret and organise their own confidence sources, not least those relating to highly variable temporal and socio-spatial frames within which a potential confidence source might be considered "relevant" or "useful." These findings contrast significantly with others emanating from research in the elite domain and, it is contended, have direct practical implications for both physical educators and grassroots sport coaches.
\end{abstract}

Keywords: Amateur sport, association football, confidence, confidence-sourcing, qualitative psychology, soccer.

\section{INTRODUCTION}

Confidence is one of the major contemporary concerns in the psychology of sporting performance [1-5]. Extant research indicates that it is strongly linked to issues at both ends of the performance spectrum; to sudden declines in performance efficacy [6] and also to the development of strong coping strategies in athletes $[2,7]$. Consequently, the "sources" of confidence (i.e. the people, things, rituals and so forth from which athletes draw psychological strength) have received progressively greater attention within the germane research corpus. It is, however, the unambiguous case that, within this literature, the main substantive concern has been with confidence in elite and/or individual sports [7-10]. Moreover, a principally deductive methodological framework has been dominant. In short, the mathematical explication of the direct relationships between confidence variables and performance in these (elite) athletes has been accorded primacy $[1,6,11]$.

Although this work has produced a range of valuable findings to date, there has been limited attention accorded to the issue of confidence in non-elite and/or team sports. The importance of understanding the methods and motivations of participants in grassroots sport is, however, bordering on the self-evident. In terms of soccer itself, at the beginning of the current decade (and despite an actual decrease in participation over the previous ten years) more than two million adults, in over 30000 amateur teams, were still playing

*Address correspondence to this author at the Department of Medical and Sport Sciences, University of Cumbria, UK; Tel: 01524 384427;

Fax: 01524 384385; E-mail: paul.miller@cumbria.ac.uk "regularly" in England alone [12]. This level of participation has obvious and large-scale implications for public health, social relations and so forth. To understand the manner in which amateur participants gain confidence (or do not) in sports themselves - and in their wider lives from them sheds important light on, for example, a key factor in improving and sustaining engagement in, or potentially reducing drop-out from, healthy physical activity. Notwithstanding some recent and innovative contributions to the field [10, 13], however, there has there been little sustained programme of inductive investigation exploring the nuanced ways in which athletes at any level organise and interpret their own confidence and confidence-sourcing.

\section{Self-Efficacy, Self-Confidence and Sport-Confidence: Some Issues of Definition}

Although the influence of Harter's [14] Perceived Competence Model should not be overlooked, it is relatively uncontroversial to suggest that the bulk of research relating to sources of sporting confidence which has been conducted in recent years takes as its conceptual touchstones either (a) Bandura's self-efficacy theory $[15,16]$, and/or (b) the sportconfidence model initially outlined by Vealey [17], and subsequently developed into a more explicitly social-cognitive framework by Vealey and colleagues [11]. These approaches are by no means mutually exclusive. At the most fundamental level, the core constructs (self-efficacy and sportconfidence) are similarly defined; both encapsulate the individual's belief/judgement that (s)he can/will perform successfully in pertinent activity or activities. Moreover, both constructs are taken to be essentially cognitive in character, "...mechanisms through which individuals mediate their 
motivation and behavior within a goal context." [18]. It is of note, however, that while Bandura's understanding of selfefficacy is highly context-specific in a number of ways (i.e. exploring confidence sources and impacts within narrow domains, such as "a sport"), more recent work in sport psychology conceptualises self-confidence as a multidimensional phenomenon, with athletes able to gain (or lose) performance-confidence in line with a multitude of factors, including those arising in the non-sporting domains of the athlete's life. Hays et al. [7], for example, argue that “...the sources from which athletes derive their confidence are not only sport specific, but also influenced by demographic and organisational factors." From this perspective, it may well be viewed, the categorisation of "sport-confidence" as a discreet phenomenon, a thing in-and-of-itself, is somewhat problematic.

Such issues highlight a key problem in the psychology of confidence in sport, and for the corollary understanding of confidence-sourcing: i.e. is "sport-confidence" a "thing" we can effectively measure? Instinctively, we might propose that until this fundamental question is satisfactorily answered, then sport psychologists will continue to have, as Vealey [1] suggests, "...barely scratched the surface in developing an understanding of this area." However, confidence has a strong phenomenological dimension. To "feel" confident is to be confident; thus, confidence is only as "real" as its experience, and its experience can be highly variable within and between persons and contexts. Thus, as Harvey Sacks [19] notes, the core question to ask of any such phenomenon should not be "What, in fact, is it?" but "How, and in what ways, is the concept assembled by those that it affects?" Until this matter is addressed, we are tied to ostensive pre-definition that may actually contradict the realworld experience of participants themselves [20].

Taking as touchstones the interpretative investigations conducted by Hays et al. [13] and Thomas et al. [10], this paper reports findings from a broader study of confidence in team sports. Employing a thematic approach that draws extensively upon the analytic techniques of Straussian Grounded Theory [21], investigation manifestly focuses upon elucidating the key phenomena and processes from which - and through which - individuals draw their own confidence to play. Adopting no a priori stance on the character of "confidence" itself, analysis derives category-definitions and process-descriptions exclusively from the participants' own verbal accounts. It is contended that the results have direct import for the experiential understanding of confidence in amateur soccer itself, and practical relevance for physical educators and coaches in broader grassroots sport.

\section{MATERIALS AND METHODS}

\section{Participants}

With institutional ethical approval, participants $(n=14)$ were purposively recruited from two amateur soccer teams in the north west UK, with the sample evenly split between males $(n=7)$ and females $(n=7)$. Both teams were approached for willing participants, of which the first seven from each team to acknowledge their interest were selected. All participants had been playing at amateur level for a minimum of one year, and all were over 18 years of age (see Table 1 for a summary of means and standard deviations in age and experience).

Table 1. Participant sample characteristics.

\begin{tabular}{|c|c|c|c|c|c|}
\hline \multirow{2}{*}{ Male } & \multirow{2}{*}{7} & \multicolumn{2}{|c|}{ Age (Years) } & \multicolumn{2}{c|}{ Experience (Years) } \\
\hline \hline \multirow{2}{*}{ Female } & \multirow{2}{*}{7} & Mean & 21.43 & Mean & 10.57 \\
\cline { 3 - 6 } & & SD & 1.81 & SD & 4.47 \\
\cline { 3 - 6 } & & Mean & 24.43 & Mean & 11.86 \\
\hline \multirow{2}{*}{ Sample } & \multirow{2}{*}{14} & Mean & 22.93 & Mean & 11.21 \\
\cline { 3 - 6 } & & SD & 3.75 & SD & 4.23 \\
\hline
\end{tabular}

\section{Materials}

Prior to the main study, two exploratory pilot interviews were conducted to facilitate development of open-ended, semi-structured interview schedules [22]. The resultant schedules were then reviewed and revised by the second author, and then reviewed by a further researcher specialising in sport psychology to verify content and structure, before a final draft was generated for use in the primary tranche of data collection. The final interview schedule was based around open questions designed to give participants space to conceptualise their confidence sources as freely as possible. Clarification and elaboration probes were used throughout, mostly to encourage reflection on answers and provision of specific examples from participants' own experience. Although it was made clear to all participants that the interview was fundamentally about the playing of soccer, the questions were phrased in a much broader manner to encourage participants to link confidence-related phenomena in soccer to their wider lifeworlds.

Prior to the interviews, all participants were sent an interview pack, containing pertinent consent-gaining documentation and a summary of the interview schedule to (a) facilitate participant reflection on experiences of being confident in advance of the interview itself and, thus, (b) to aid participants in providing considered detail that might not have manifested with the use of "unseen" questions [13]. Moreover, to minimise the risk of subject bias, each participant was explicitly assured that their answers would be fully anonymised, and that they did not have to answer a question or address a topic if they did not wish to.

\section{Procedure}

Interviews lasted between 16 and 32 minutes $(\mathrm{m}=26$ minutes, 33 seconds), and all were conducted in a location of the participant's choosing to ensure maximum environmental comfort. The interviews were transcribed verbatim, producing approximately 53,000 words of qualitative data in total. Following each interview, respondent validation [23] was 


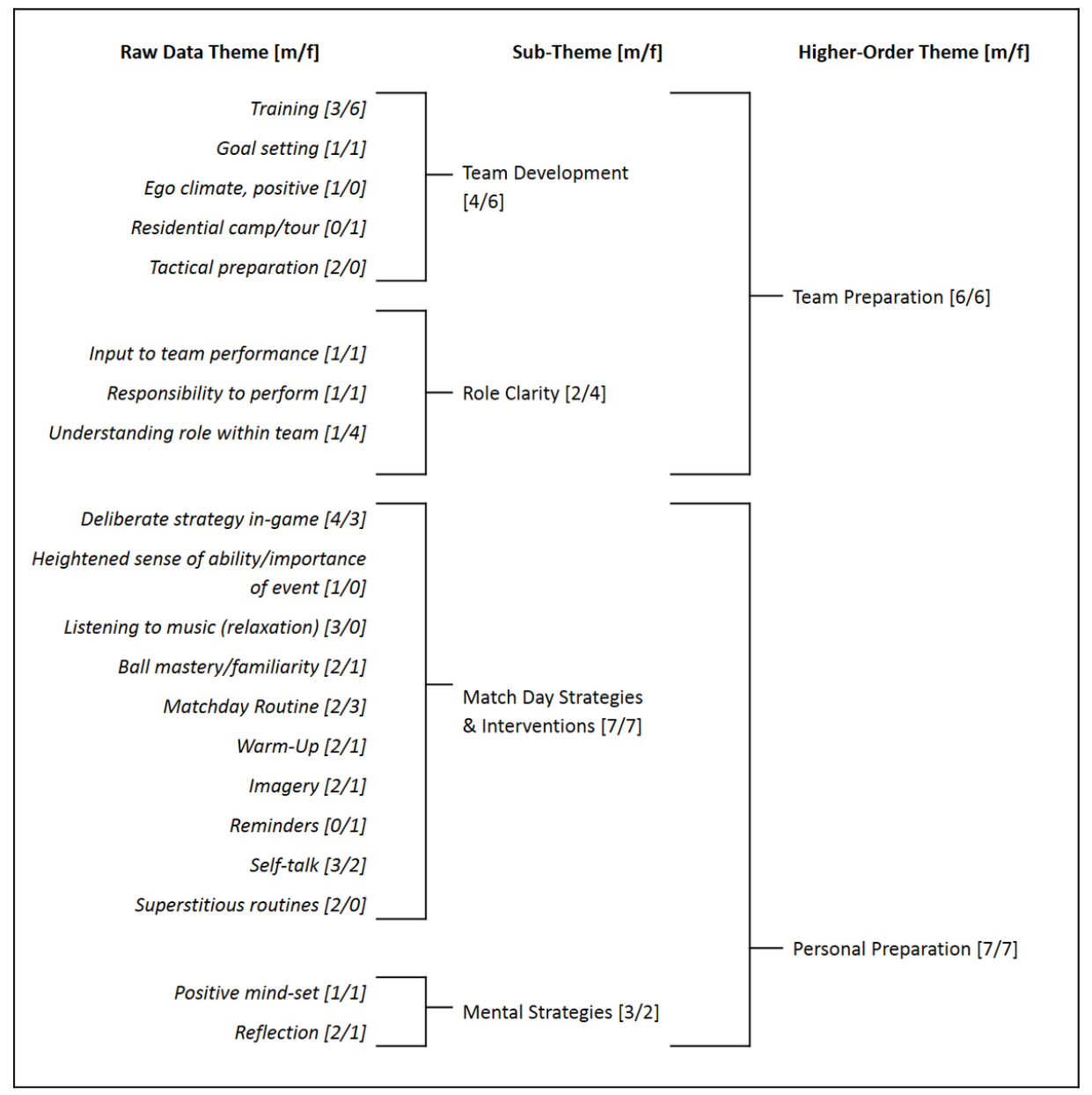

Fig. (1). Global theme 1 - Preparation.

obtained by sending a verbatim transcript to all participants for verification of exactitude and representativeness. Participants were invited to correct mistakes or misinterpretations, and all formally concurred that the transcripts were accurate reflections of their words.

In line with the principles outlined by Strauss and Corbin [21], open coding was initially employed to identify themes, ideas and meanings contained within the data, while axial coding was then used to identify connections between categories. Emerging from the total data corpus were 911 meaning units, which were subsequently categorised into 139 rawdata themes. These were grouped into 30 overlapping subthemes and higher-order themes, before finally being categorised into (cross-linking) global dimensions. Of these global dimensions, 4 related directly to confidence sources, and are addressed in this paper ${ }^{1}$. The global dimensions were deductively re-applied to the original transcripts to ensure consistency. Moreover, participants were invited to comment upon the initial analysis of their individual transcripts to assure credibility of provisional findings through "member checks" [24]. All feedback was incorporated into the analytic framework.

\footnotetext{
${ }^{1}$ Others, pertaining to experiences of "being confident," "confidence deficit," and threats to confidence, are the topic of a forthcoming paper.
}

\section{RESULTS}

The fourteen amateur athletes' discussions of sources of confidence organised into four distinct global dimensions that manifested in equal spread across both genders. These are outlined, in turn, below. Herein, and in a similar vein to Thomas et al. [10], the numbers of male and female participants citing each confidence source shown are in brackets $(\mathrm{M} / \mathrm{F})$. While frequency counts are noteworthy in their ability to illuminate which sources were most commonly-cited, there is no analytic judgement on relative "importance" made as a consequence; after all, the fact that a source is "unusual" does not make it any less meaningful to the individual who draws strength from it. The inclusion of every source cited, meanwhile, serves to highlight the sheer range of matters, people and practices from which the amateur athletes gain confidence. The included frequency counts may thus enable researchers to draw their own conclusions regarding the transferability of findings to other settings [13], but should not be conceptualised as any indicator of the "overall relevance" of an issue.

\section{Preparation}

The matter of preparation was evident in many forms, but chiefly split across two higher-order themes of team preparation and personal preparation, as illustrated in Fig. (1). The very notion of preparation was indicated by participants to 


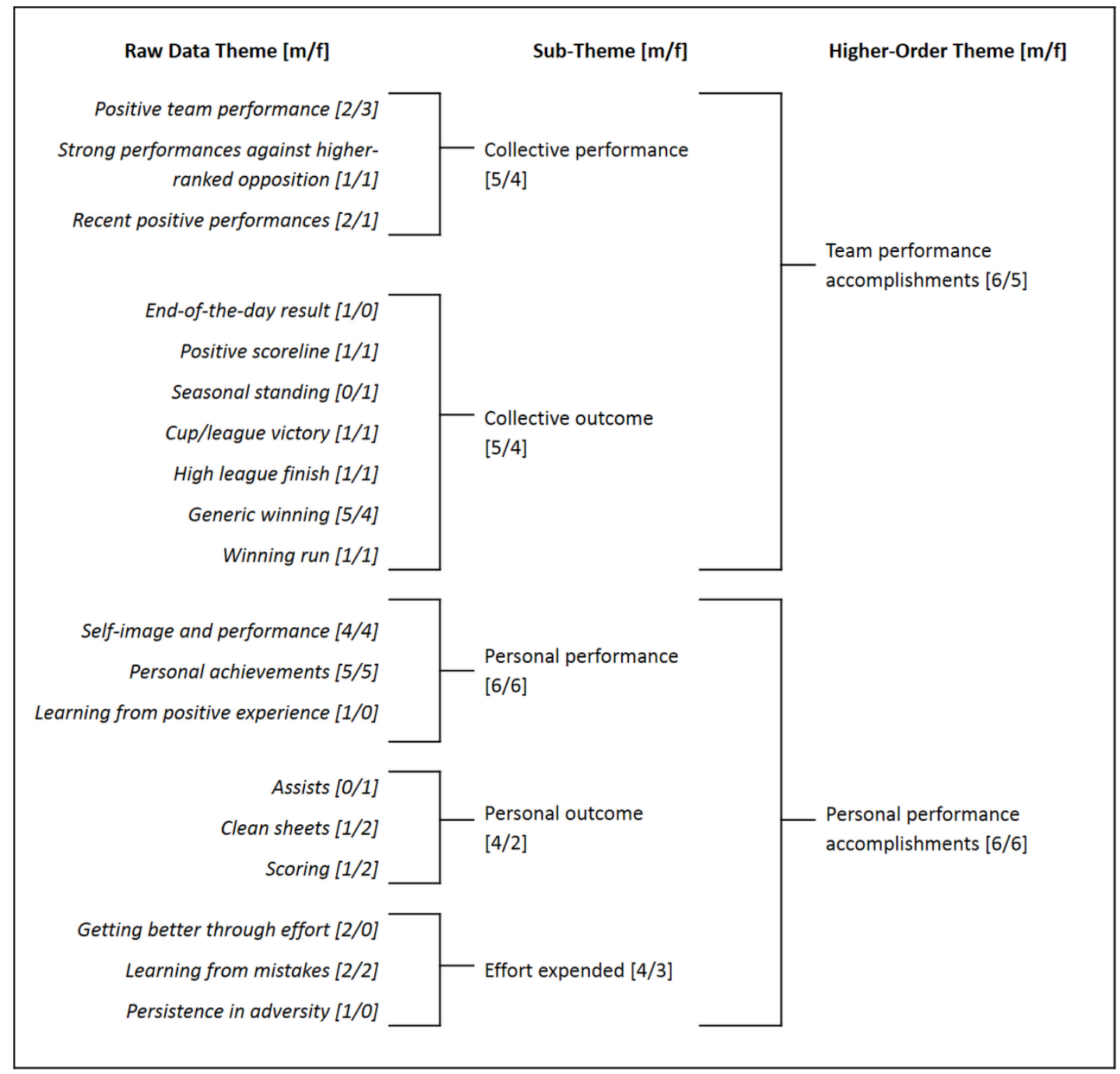

Fig. (2). Global theme 2 - Inferred performance accomplishments.

be time-specific, and included activities in the period leading up to the day of a game, on the day of a game itself and also post-game (i.e. reflection). All participants claimed to employ confidence-enhancing match-day strategies as part of their personal preparation, which included the use of selftalk, music and "superstitious" rituals.

The importance of general team development as a confidence source, highlighted by more females than males (males, $n=4$; females, $n=6$ ), was discussed in terms of both training and role clarity. In terms of the latter, Lolly ${ }^{2}$, for example, stated that "...you have to know your roles and what you're doing - your responsibilities," while Maria identified a source of confidence as being when she "...felt like [she] knew how the team were going to play, and [she] felt like [she] knew what [her] role in that team was." Effective pre-game training was also seen as an important confidence source by more females than males (males, $n=3$; females, $n=6$ ), though specific tactical preparation for matches was raised by far fewer (males, $\mathrm{n}=2$; females, $\mathrm{n}=0$ ).

\footnotetext{
${ }^{2}$ This, and in all cases whereby a participant is directly referred to by name, is a pseudonym of the participant's own choosing.
}

\section{Inferred Performance Accomplishments}

Of the fourteen participants, twelve cited their inferences regarding prior and likely performance accomplishments as sources of confidence (see Fig. 2). These included both team and personal achievements, and were divided between process (i.e. effort and performance) and outcome dimensions. "Winning as a team" (male, $n=5$; female $n=4$ ) was consistently raised as a prime means by which team accomplishment could be judged and, as an outcome, both personal and group confidence lifted for future endeavours. Sarita claimed "...our ten game unbeaten-run makes you go into every week feeling more confident." Positive personal performances, meanwhile, were widely deemed to contribute to confidence, but on a personal rather than collective level. In short, less personal confidence was drawn directly from other members of the team having "good games" than from the team winning.

Not all performance accomplishment was evaluated in terms of results, however; half of the participants (males, $\mathrm{n}=4$; females, $\mathrm{n}=3$ ) maintained that they drew confidence from the expenditure of effort alone. To have "worked ones hardest," even in losing circumstances, could be a genuine 


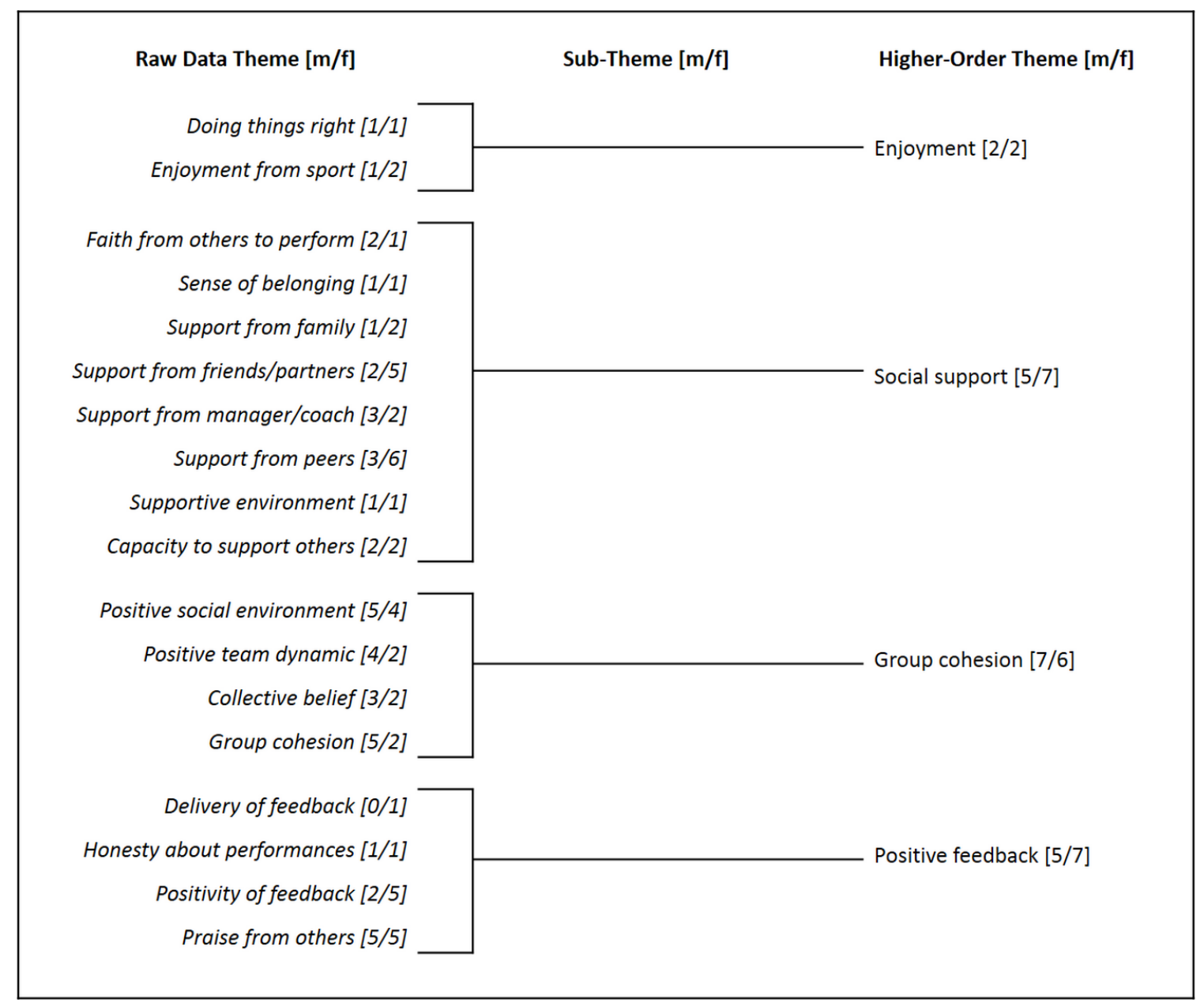

Fig. (3). Global theme 3 - Positive team environment.

source of uplift or, at the very least, an attenuator on confidence damage. In a similar vein, mistakes themselves were taken to have a positive aspect if learned-from (males, $n=2$; females, $n=2$ ).

\section{Positive Team Environment}

All fourteen participants designated a positive team environment and support from team mates as a centrally important source of confidence to play, as evidenced in Fig. (3).

A positive atmosphere within the team itself, and practical team cohesion, was deemed to be a confidence-booster by thirteen of the fourteen participants. For example:

Clive: "It helps if your team mates, if you get on with them all, if it's a nice cohesive group."

Jenny: "I think as a team we've been working hard, and I think if you're confident together you'll win together."

More females than males (male, $n=5$; female, $n=7$ ) alluded to the importance of broader social support external to the team itself, specifically that from friends and partners, though it was also acknowledged by a number of participants that the two domains were not necessarily mutually exclusive. Sandra, for example, stated that “...obviously it's a team game isn't it? You get confidence from your friends, and they're your friends as well as your team mates." The support of the coach/manager as a generator of confidence, on the other hand, was raised by less than half of the participants (male, $n=3$; female, $n=2$ ) and, among these, was not qualitatively emphasised to the same extent as team mates or other peers.

Feedback from peers within the team was also a common theme raised by both genders; outright praise was viewed as a major source of confidence to ten participants (male, $n=5$; female, $n=5)$, while more females than males explicitly cited the value of positive, constructive feedback (males, $n=2$; females, $n=5$ ) in building a confident approach.

\section{Belief in Individual and Collective Performance Capacity}

General positive beliefs about individual and collective abilities to perform, grounded in (ideally recent) evidence, were the final global aspect of the participants' descriptions of confidence-sourcing. Confidence of this order knowledge was taken to stem from knowledge of the range of abilities within the team, self-awareness of capacities, knowledge of the opposition in forthcoming games and particularly the comparison to make lateral comparisons on this basis, as shown in Fig. (4). 




Fig. (4). Global theme 4 - Belief in individual and collective performance capacity.

Six of the participants maintained that they were likely to gain confidence from holding faith in their team mates to perform, though not in an even gender balance (males, $n=2$; females $n=4)$. Sarita, for example, identified that confidence could rise when one is "...confident that the people around you are going to do a good job. ” Belief in one's own capacity to perform, however, was a universal theme and in all cases deemed to be ultimately more influential in terms of the generation of confidence to play than belief in the capacities of others. For example:
Lolly: "I know what I can do and how I can perform to my best levels."

Jamal: "[I] gain more confidence from believing in myself and believing I can do things."

Of some note is that eight of the participants, in equal gender balance, drew confidence from the belief that they either had impressed, or would impress, spectators and existing/potential "romantic partners" by playing well. However, a preoccupation with "looking the part" while playing was 
voiced as a rather more profound concern among females (males, $\mathrm{n}=1$; females, $\mathrm{n}=5$ ). For example, Jenny's claim that "I want to look the best I can and feel good..."

Participants cited as a key source of confidence the belief that they have outperformed, or will outperform, others both within (males, $n=3$; females, $n=3$ ) and external to (males, $n=4$; females, $n=3$ ) the team. Colin noted "If I feel like I'm one of the better players, that's a big thing for me," while Dorris argued that "I'm confident because...I can play and some of them can't." While these participants were able to draw confidence from a generic belief in their capacity to simply "play a better game" than others on the pitch, some were more circumspect in their comparisons. Consider this reflection, for example:

Jenny: "[Y]ou can't directly compare yourself to someone if they're playing a different position but you can kind of see what boxes in their position they're ticking and then what you are, and then you can compare the two and see how well you're doing in comparison to someone else."

In terms of extra-team comparisons, it was not only the belief in a prospective opposition's inability to play that was deemed a boon to confidence; simply holding knowledge of another team's abilities was viewed to be a similar fillip (males, $n=4$; females, $n=4$ ) as it facilitated planning and better preparation.

\section{DISCUSSION}

The present research illustrates that preparation is as a common and multifaceted source of confidence among the participating amateur athletes. As also reported by Hays et al. [13] and Vealey et al. [11], such confidence-creating preparation has both the physical (e.g. warm-up) and psychological (e.g. self-talk) dimensions. Multi-faceted preparation has also been identified by coaches and trainers as having a positive impact on performance [25]. This source of confidence emerges, thus, from both qualitative and quantitative investigations, and with respect to team and individual sports, and amateur and elite athletes. Thus, it would appear to be a transferable source of confidence. It is noteworthy, however, that the preparation rituals and strategies outlined by participants in this particular study were always temporally-specific in character, which raises another key matter.

There is growing body of investigative work that has empirically attended to the matter of timing in sport-oriented confidence-sourcing [18]. Findings reported here support extant assertions that the temporal situation of confidenceenhancing phenomena (be they people, totems or processes) can be just as significant to participants as the qualitative and quantitative natures of the phenomena themselves. In short, it is one thing for things to be "right" or "in the right amount," and another for them to be present "at the right time." A novel matter that arose in the results reported above, for example, was the importance of what we might term preparation after-the-event. This type of preparation had a retrospective-prospective character, i.e. it was tasked towards projected future events, but grounded in reflection on events just-past. Research specifically considering temporal variance in this domain should perhaps, thus, consider this to be an additional form of preparation. Moreover, such research might also be directed towards the detailed mapping of when each preparation source actually begins to become salient to participants. For example, and intuitively, personal preparation (match day and mental strategies) may be particularly important close to the event, while team preparation might be a longer-term source of confidence. Firm empirical data of this nature could have great import for the practices of coaching and, indeed, for broader motivational sport psychology.

Inferred performance accomplishments were found to be a major source of confidence among participants, in a manner akin to the "demonstration of ability" factor reported by Vealey et al. [11]. Such confidence-raising was found in what the participants regarded to be process and outcome accomplishments. For example, participants highlighted the importance of the effort they expended and their ongoing qualitative performance as much as they did winning and results. This observation has the capacity to inform future deductive work, in terms of how one might measure the incidence of occurrence for such sub-categories. Measures of sporting outcome as a source of confidence may well continue to find frequency counts an adequate tool. To measure process-factors as sources of confidence, however, inherently requires that, once again, a researcher attend intimately to issues of temporality. Time intervals are potentially, thus, hugely important when considering future metrics for sport confidence.

Linked to the process of expending effort, noted above, was the assertion by half of the participants that confidence stems from a simple awareness that one has worked ones hardest. This appears to be a more salient source of confidence in amateur athletes than in their elite counterparts. Although to have "given ones all" is a mitigating rhetorical device often used by elite athletes when accounting for failure $[26]^{3}$ in, for example, post-match interviews and press conferences, there is little empirical evidence that any formal confidence is drawn from it. Given that elite athletes are often performing under significant pressure to win in a "results-oriented" business [27], one may suspect that for an athlete to have simply worked their hardest might not be satisfactory in this regard.

With regard to the stability or robustness of a state of confidence, meanwhile, the distinction between effort and result becomes particularly germane. Thomas et al. [10] argue that an individual's control over a source of confidence directly relates to its importance in the formation of stable confidence. While elite athletes can, thus, draw upon a reasonably solid (i.e. well-measured and coached) understanding of their own ability [13], amateurs may instead have to draw upon something they can themselves conceptualise more solidly, i.e. the amount of effort they have actually expended relative to the amount they infer they could potentially have expended. This illustrates variability in the construction of confidence sources from one organisational setting to another. Furthermore, it illustrates that the sources of confidence which are "stable" from one context - and one athlete - to another may also be very different. This observation has clear implications for practitioners who subscribe to

\footnotetext{
${ }^{3}$ Locke [26] provides a detailed exploration of the use of such discursive tools in accounting for performance outcomes.
} 
the position that confidence should be entirely built upon "controllable" sources [10].

The positive team environment cited by all participants as a source of confidence shares several similarities with the "social support" and "environmental comfort" factors discovered by Vealey et al. [11]. Social support from a group wider than those directly involved in the sport was also considered a source of confidence for amateur participants, as was similarly acknowledged by Hays et al. [13] with respect to elite athletes. The importance of positive team and social environments, as sources of confidence, is thus, and perhaps unsurprisingly, supported in a sample composed entirely of team sport players. Within this broad domain, however, there is some telling nuance.

Firstly, in the present study, support and feedback from peers was discussed more frequently by participants, and more extensively qualitatively emphasised, than support and feedback from coaches. Gould et al. [9] note that, at the elite level, the credibility, enthusiasm, and knowledge of coaches are all critical to high-level athletic success, and a fundamental source of confidence for athletes themselves in both individual and team sports. Indeed, the coach-athlete relationship actually formed a distinct global dimension in the study of elite athletes conducted by Hays et al. [13]. The amateur participants interviewed for this study, however, although all playing for teams with formal coaches, configured their own confidence-sourcing rather differently.

There are a number of reasons why this discrepancy may have emerged. It is entirely possible that the amateur participants may simply consider sport to be more of a social phenomenon than their elite counterparts ${ }^{4}$. It may also be a reflection on their implicit positioning of the coach him/herself as a non-professional, and therefore differentiating less between the roles of coach and athlete (and the assumed expertise immanent therein) than might be the more formalised case at higher levels. There is little doubt that this matter alone demands systematic investigation and, moreover, raises questions relating to the processes through which athletes move from amateur environments to elite ones. We might ask if there is therefore a disjunction-point at which athletes switch from drawing greater support from peers to sourcing confidence primarily from their coach, or if the process is gradual. Stronger longitudinal understanding of the manner in which athletes organise their confidencesourcing could help contribute extensively to the broader body of knowledge on coach-athlete relationships.

Secondly, confidence drawn from (a) broader social support and (b) positive feedback was considerably more strongly emphasised among the female participants in the study than among the males. The former resonates with the claim by Vealey et al. [11] that females generally draw more sporting confidence from everyday social support. Regarding the latter, both Hays et al. [13] and Vealey et al. [11] contended that females view a coach's roles in confidencegeneration mostly in terms of its capacity to provide them with affirmative response. Although, among the amateur participants, coaching itself was regarded a less fundamental

\footnotetext{
${ }^{4}$ Particularly given that, with all participants still in amateur football at the ages of $18+$, it is unlikely that many would (still) view playing as a serious conduit to a professional career.
}

source of confidence, similar gender differences regarding feedback still emerged, only with peers as the key contributing agents. It should be noted that social support per se was recurrently cited by both genders, and as in past research [11, 13], would appear to be a robust source of confidence for both males and females, despite some gender differences in the exact expression of social support.

Faith in one's own ability and likelihood to perform constituted part of the final source of confidence documented in the present research. This matter is akin to Bandura's [16] early conception of self-efficacy, which proposed that confidence was ones belief that a level of performance could be attained. However, a testament to the multi-dimensional nature of sport confidence is that it was found as one of four sources of confidence in total. This also is in accordance with Vealey et al.'s [11] contentions that sources of confidence can exist over-and-above Bandura's [16] self-efficacy predictors. Moreover, the present research reveals that not only does such a belief in oneself function as a source of confidence, but also a belief in one's team.

Drawing confidence from faith in ones team-mates to perform to a suitably high standard is similarly recognised by Hays et al. [13], though classified as an issue of "Trust." Vicarious sources of confidence such as this have, indeed, been regularly reported by research pertinent to elite teambased activities [28, 29]. The findings of the present study indicate that among amateur athletes, with fewer hard performance measures available with which to support such trust/belief, the projected performances of others nonetheless remain a strong source from which confidence can be drawn. In short, one does not have to believe that team-mates are "good" by any objective standards, but simply that they are "good enough" to do the job in context. This relativistic reasoning also highlights how a context-sensitive approach to confidence-raising can be a powerful tool for sport coaches outside of the elite domain. One does not, it appears, require hard quantitative measures or performance analysis outputs to generate trust in the ability of others; indeed, the capacity of participants to address singular qualitative cases of strong performances by team mates as evidence that these would recur "when it mattered" would seem to indicate a rather more heuristic than "systematic" approach to finding evidence for such beliefs [30,31]. In short, the vivid example would seem to be a more powerful boon to confidence among sporting participants at this level than the "factual evidence" more commonly relied upon by elite coaches and sport scientists in their decision-making [32].

Although vicarious confidence was a strong theme in the data, belief in the self was ultimately more firmly emphasised by participants when attributing sources of confidence. This is, perhaps, unsurprising. In studies designed to dimensionalise "mental toughness," self-belief has consistently emerged as the key attribute [29, 33]. Considering teams holistically, this may indeed prove to be a reflexive, cyclical process. Strong self-belief in some athletes may well contribute to a stronger general motivational climate [34] which, in turn, can act as a further source of confidence for individuals. Additionally, in terms of robust confidence, this cyclicality may provide a strategy for the maintenance of positivity, which has clear ramifications for the practices of coaching and leadership in group sport at all levels. 
Finally, "looking the part," what Vealey et al. [11] describe as the matter of "self-presentation" among collegiate athletes, was found to be a source of confidence for many of the amateur participants in the present research. Hays et al. [13], however, were unable to find a parallel source for elite athletes, and tentatively propose that it may be the links between non-elite sports and social life that raise the salience of self-presentation for participants. It might be expected that elite athletes would derive confidence from substantial fiscal and social rewards, while amateurs are limited to the social. This evidence, however, suggests that an exclusivity mechanism is actually in play. In short, social rewards such as wider peer-esteem (including that from potential "romantic partners") are treated as key confidence sources by amateurs, while barely at all by elite performers. This may be a function of a deprioritisation of general social bonds (often framed as "distractions") encouraged among high level athletes, and also those aspiring to that level [35], a process which is largely absent at the grassroots of sport. Critically, however, it may well explain why it has been feasible for studies based purely upon elite performers to treat the construct of "sport-confidence" as a (relatively) discreet entity, while the data reported above from outside of the elite domain - in line with the proposals of Hays et al. [7] - display strong interlacing of confidence sources from on and off the field.

\section{CONCLUSION}

In sum, the research reported above begins from the proposition that the categorisation of sport-confidence as a discreet phenomenon, a "thing" in-itself, is problematic. The analytic enterprise therein, thus, is targeted at understanding how confidence-sourcing in amateur sporting environments is actively assembled and interpreted by the individuals it affects. The inductive approach employed resulted in the identification of a range of issues pertinent to sources of confidence for these participants, ranging from the heuristic nature of "evidence selection," to the importance of temporal positioning in a confidence-source. It is not difficult to imagine how such matters may not have been so clearly elucidated within a deductive framework.

Similarly, many of the various confidence sources identified appeared to be qualitatively novel to team sports as opposed to individual, and to amateur athletes as opposed to elite. This lends considerable weight to a conceptualisation of confidence itself as a highly eclectic, contextually-driven phenomenon. While this may ostensibly appear to be an obstacle to practical intervention, there is little empirical evidence to suggest that a "one size fits all" model for confidence-boosting in sport coaching or physical education, for example, was ever a realistic goal. Rather, it highlights the need for grassroots coaches and teachers to work within the lifeworlds of their charges, rather than rely too extensively on pre-ordained frameworks. This involves understanding of how individual athletes interpret their own confidencesourcing in-context, and also how they interpret contexts themselves [20]. For example, and as noted above, there is a propensity among many elite coaches to determine what constitutes "strong (or weak) performance" in a somewhat statistical manner (especially where the tools of performance analysis are available to them). The findings relating to ama- teur soccer presented here, however, indicate that the vivid example of strong performance (in self and others) can be a very strong heuristic boon to a player's confidence. Thus, for the coach of an amateur team, or a physical educator, to provide one of their charges with performance-related evidence from which they can draw confidence, that coach/teacher needs to be mindful of the kind of evidence that might be best received and acted upon. In this respect, the unavailability of the formal performance analytic tools commonly used in the elite game need not be maligned as a serious shortcoming. Moreover, what might constitute a "vivid" example of strong performance to any given individual itself emerges as a matter of interpretation. Is the example drawn from within a timeframe that the athlete is able to conceptualise as relevant to the "now," we might ask; is it specifically meaningful to them personally, and is it from an inferably transferrable context? To have excelled at penalty kicks in training a week ago might raise confidence in open play today for some, but for others it may simply not be vivid or relevant. In this sense, empathy and personal rapport, tools readily available to pedagogical agents at the grassroots level, become ever more valuable.

In academic terms, meanwhile, the findings above should not be viewed pessimistically, as further evidencing the difficulty in generating strong models of confidence-sourcing in sport observed by Vealey [1]. Rather, they should be seen as additional issues of which we can be aware when approaching the practical business of understanding the dimensions of confidence in sporting contexts; in Herbert Blumer's [36] terms, "sensitizing concepts." Like other key inductive findings currently emerging in the domain, they are points of departure from which further research can be launched in the long-wave journey towards genuinely robust, defensible and context-sensitive grounded theories.

\section{CONFLICT OF INTEREST}

The authors confirm that this article content has no conflict of interest.

\section{ACKNOWLEDGEMENTS}

\author{
Declared none
}

\section{REFERENCES}

[1] Vealey RS. Understanding and enhancing self-confidence in athletes. In: Singer R, Hausenblas H, Janelle C, Eds. Handbook of Sport Psychology. New York: Wiley 2001: pp. 550-65.

[2] Fransen K, Vanbeselaere N, Cuyper BD, Slater MJ, Boen F, Coffee P. The impact of athlete leaders on team members' team outcome confidence: A test of mediation by team identification and collective efficacy. Sport Psychol 2014; 28: 347-60.

[3] Nazari B, Mohammadi S, Yektayar M. The relationship between self-confidence and sport commitment with sport identity in the elite gymnasts. Choregia 2013; 9: 67-75.

[4] Lane A. An examination of robust sport-confidence in elite sport. Sport Exerc Psychol Rev 2014; 10: 24-7.

[5] Podlog L, Hannon JC, Banham SM, Wadey R. Psychological readiness to return to competitive sport following injury: A qualitative study. Sport Psychol 2015; 29: 1-14.

[6] Hays K, Thomas O, Maynard I, Butt J. The role of confidence profiling in cognitive-behavioral interventions in sport. Sport Psychol 2010; 24: 393-414. 
[7] Hays K, Thomas O, Maynard I, Bawden M. The role of confidence in world-class sport performance. J Sports Sci 2009; 27: 1185-99.

[8] Wilson RC, Sullivan P, Myers ND, Feltz DL. Sources of sport confidence of master athletes. J Sport Exerc Psychol 2004; 26: 36984

[9] Gould D, Guinan D, Greenleaf C, Medberty R, Peterson K. Factors affecting olympic performance: Perceptions of athletes and coaches from more and less successful teams. Sport Psychol 1999; 13: 37194.

[10] Thomas O, Lane A, Kingston K. Defining and contextualizing robust sport-confidence. J Appl Sport Psychol 2011; 23: 189-208.

[11] Vealey RS, Hayashi SW, Garner HM, Giacobbi P. Sources of sport-confidence: Conceptualization and instrument development. J Sport Exerc Psychol 1998; 20: 54-80.

[12] Sport England. Active People Survey (APS) Results for Football. Period: APS2 (Oct 07 / Oct 08) to APS4 (Oct 09 / Oct 10). London: Sport England 2010.

[13] Hays K, Maynard I, Thomas O, Bawden M. Sources and types of confidence identified by world class sport performers. J Appl Sport Psychol 2007; 19: 434-56.

[14] Harter S. Effectance motivation reconsidered: Towards a developmental model. Hum Develop 1978; 12: 87-97.

[15] Bandura A. Self-Efficacy: The exercise of control. New York: W.H. Freeman 1997.

[16] Bandura A. Self-efficacy: Toward a unifying theory of behavioral change. Psychol Rev 1977; 84: 191-215.

[17] Vealey RS. Conceptualization of sport-confidence and competitive orientation: Preliminary investigation and instrument development. J Sport Psychol 1986; 8: 221-46.

[18] Kingston K, Lane A, Thomas O. A temporal examination of elite performers sources of sport-confidence. Sport Psychol 2010; 24: 313-32.

[19] Sacks H. On sociological description. Berkeley J Sociol 1963; 8: 116

[20] Miller PK, Cronin C. Rethinking the factuality of "contextual" factors in an ethnomethodological mode: Towards a reflexive understanding of action-context dynamism in the theorisation of coaching. Sport Coach Rev 2013; 1: 106-23.

[21] Strauss A, Corbin JM. Basics of qualitative research: techniques and procedures for developing grounded theory. $2^{\text {nd }}$ ed. London: Sage 1998.
[22] Charmaz K. Grounded theory. In: Smith JA, Ed. Qualitative Psychology: A Practical Guide to Methods. London, Sage 2008: pp. 81-110.

[23] Silverman D. Interpreting qualitative data: methods for analysing talk, text and interaction. $3^{\text {rd }}$ ed. London: Sage 2006.

[24] Guba EG, Lincoln YS. Fourth generation evaluation. Newbury Park: Sage 1989

[25] Greenleaf C, Gould D, Dieffenbach K. Factors influencing Olympic performance: Interviews with Atlanta and Negano US Olympians. J Appl Sport Psychol 2001; 13: 154-84.

[26] Locke A. Accounting for success and failure: A discursive psychological approach to sport talk. Quest 2004; 56: 302-20.

[27] Fletcher D, Hanton S, Mellalieu SD. An organizational stress review: Conceptual and theoretical issues in competitive sport. In: Hanton S, Mellalieu SD, Ed. Literature Reviews in Sport Psychology. Hauppauge, NY: Nova Science 2006: pp. 1-45.

[28] Hardy L, Jones G, Gould D. Understanding psychological preparation for sport: theory and practice of elite performers. Chichester: John Wiley \& Sons 2001.

[29] Jones G, Hanton S, Connaughton D. What is this thing called mental toughness? An investigation of elite sport performers. J Appl Sport Psychol 2002; 14: 205-18.

[30] Miller PK, Rowe L, Cronin C, Bampouras T. Heuristic reasoning and the observer's view: The influence of example-availability on ad-hoc frequency judgments in sport. J Appl Sport Psychol 2012; 24: 290-302.

[31] Bennis WM, Pachur T. Fast and frugal heuristics in sports. Psychol Sport Exerc 2006; 7: 611-29.

[32] Bampouras T, Cronin C, Miller PK. Performance analytic processes in elite sport practice: An exploratory investigation of the perspectives of a sport scientist, coach and athlete. Int J Perform Anal Sport 2012; 12: 468-83.

[33] Bull SJ, Shambrook CJ, James W, Brooks J. Towards an understanding of mental toughness in elite English cricketers. J Appl Sport Psychol 2005; 17: 209-27.

[34] Duda JL. Motivation in sport settings: A goal perspective approach. In: Roberts GC, Ed. Motivation in sport and exercise. Champaign, IL: Human Kinetics 1992: 57-91.

[35] Coakley J. Burnout among adolescent athletes: A personal failure or social problem? Sociol Sport J 1992; 9: 271-85.

[36] Blumer H. What is wrong with social theory? Am Sociol Rev 1954; 18: 3-10.

This is an open access article licensed under the terms of the Creative Commons Attribution-Non-Commercial 4.0 International Public License (CC BY-NC 4.0) (https://creativecommons.org/licenses/by-nc/4.0/legalcode), which permits unrestricted, non-commercial use, distribution and reproduction in any medium, provided the work is properly cited. 